\title{
RESEARCH
}

Open Access

\section{Tracking of total sedentary time and sedentary patterns in youth: a pooled analysis using the International Children's Accelerometry Database (ICAD)}

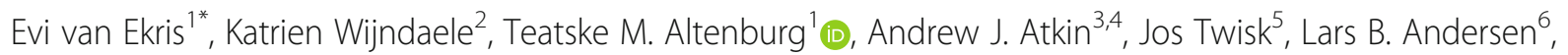
Kathleen F. Janz ${ }^{7}$, Karsten Froberg ${ }^{8}$, Kate Northstone ${ }^{9}$, Angie S. Page ${ }^{10,11}$, Luis B. Sardinha ${ }^{12}$, Esther M. F. van Sluijs ${ }^{3}$, Mai Chinapaw ${ }^{1}$ and On behalf of the International Children's Accelerometry Database (ICAD) Collaborators

\begin{abstract}
Background: To gain more understanding of the potential health effects of sedentary time, knowledge is required about the accumulation and longitudinal development of young people's sedentary time. This study examined tracking of young peoples' total and prolonged sedentary time as well as their day-to-day variation using the International Children's Accelerometry Database.

Methods: Longitudinal accelerometer data of 5991 children (aged 4-17y) was used from eight studies in five countries. Children were included if they provided valid ( $\geq 8 \mathrm{~h} /$ day) accelerometer data on $\geq 4$ days, including $\geq 1$ weekend day, at both baseline and follow-up (average follow-up: 2.7y; range 0.7-8.2). Tracking of total and prolonged (i.e. $\geq 10$-min bouts) sedentary time was examined using multilevel modelling to adjust for clustering of observations, with baseline levels of sedentary time as predictor and follow-up levels as outcome. Standardized regression coefficients were interpreted as tracking coefficients (low: <0.3; moderate: 0.3-0.6; high: >0.6).

Results: Average total sedentary time at study level ranged from 246 to $387 \mathrm{~min} /$ day at baseline and increased annually by $21.4 \mathrm{~min} /$ day (95\% confidence interval [19.6-23.0]) on average. This increase consisted almost entirely of prolonged sedentary time (20.9 min/day [19.2-22.7]). Total (standardized regression coefficient $(B)=0.48$ [0.45-0.50]) and prolonged sedentary time $(B=0.43[0.41-0.45])$ tracked moderately. Tracking of day-to-day variation in total $(B=0.04[0.02-0.07])$ and prolonged $(B=0.07[0.04-0.09])$ sedentary time was low.
\end{abstract}

Conclusion: Young people with high levels of sedentary time are likely to remain among the people with highest sedentary time as they grow older. Day-to-day variation in total and prolonged sedentary time, however, was rather variable over time.

Keywords: ICAD, Sedentary time, Accelerometer, Tracking, Children, Adolescents, Objective assessment

\footnotetext{
*Correspondence: e.vanekris@vumc.nl

'Department of Public and Occupational Health, Amsterdam Public Health research institute, VU University Medical Center, van der Boechorststraat 7, 1081BT Amsterdam, the Netherlands

Full list of author information is available at the end of the article
}

\section{$\triangle B M C$}

(c) The Author(s). 2020 Open Access This article is licensed under a Creative Commons Attribution 4.0 International License, which permits use, sharing, adaptation, distribution and reproduction in any medium or format, as long as you give appropriate credit to the original author(s) and the source, provide a link to the Creative Commons licence, and indicate if changes were made. The images or other third party material in this article are included in the article's Creative Commons licence, unless indicated otherwise in a credit line to the material. If material is not included in the article's Creative Commons licence and your intended use is not permitted by statutory regulation or exceeds the permitted use, you will need to obtain permission directly from the copyright holder. To view a copy of this licence, visit http://creativecommons.org/licenses/by/4.0/ The Creative Commons Public Domain Dedication waiver (http://creativecommons.org/publicdomain/zero/1.0/) applies to the data made available in this article, unless otherwise stated in a credit line to the data. 


\section{Background}

Children and adolescents spend the main part of their waking hours sedentary [1-3], and their sedentary time is consistently found to increase with age $[4,5]$. Cooper et al. [6] for example reported in their cross-sectional study that daily sedentary time of adolescents aged 17-18 years is approximately $25 \%$ higher compared to children aged 5-6 years. In young people, some evidence indicates that sedentary time, and in particular TV viewing time, is associated with an increased risk for overweight and decreased fitness [7] but evidence for health effects of young people's sedentary time is in general inconclusive $[7,8]$. In order to gain more understanding of potential health effects of sedentary time, more knowledge is needed about the accumulation of sedentary time and how levels of sedentary time evolve over time. Childhood may be a critical period for the development of sedentary behaviour habits $[4,9]$. This highlights the need for a better understanding of how young people's sedentary time tracks longitudinally. Tracking of sedentary time refers to the degree in which current time spent sedentary can predict time spent sedentary at a later timepoint [10]. If tracking is high, people are likely to retain their rank for sedentary time within the population over time.

Systematic reviews typically find moderate tracking of young people's sedentary behaviour $[9,11,12]$. However, the existing literature presents two main limitations. First, most studies examine tracking of TV viewing and screen time $[9,11,12]$, which are not representative of total sedentary time [13]. Only four previous studies examined tracking of objectively-assessed total sedentary time in young children, children or adolescents [4, 14-16] and found fair-to-moderate tracking of sedentary time, except for the study of Kelly et al. [16] in which low tracking of sedentary time was found in young children during the preschool-to-school transition period. Large scale international studies examining tracking of objectively measured sedentary time, using a diverse study population are currently lacking. A second limitation of the exisiting literature is the limited evidence on tracking of the pattern in which total sedentary time is accumulated. Recent experimental $[17,18]$ and epidemiological studies [19-21] in young people suggest that not only total sedentary time but also the extent to which sedentary time is accumulated in prolonged bouts (i.e. prolonged sedentary time) might be important for health. We have identified only two previous studies examining tracking of sedentary bouts; both of which examined the number of sedentary bouts [4, 15]. Janz et al. [15] found that tracking of the number of sedentary bouts (defined as bouts $\geq 5 \mathrm{~min}$ ) was slighty lower than tracking of total sedentary time, although tracked moderately. Janssen et al. [4] found that tracking coefficients for the number of bouts ranged between 0.06-0.52, depending on bout length, age of children and follow-up duration.
Tracking of the total time accumulated in bouts has not been examined before, but might be more directly related to health than the number of sedentary bouts per se [22]. Another approach to examine accumulation of sedentary time is to look at variation in sedentary time between multiple days (i.e. day-to-day variation). Generally, the average sedentary time is calculated over multiple days, but no previous studies examined tracking of day-to-day variation in sedentary time. Insight in how sedentary time is accumulated throughout the week and how this day-to-day variation tracks over time may be important to inform interventions targeting sedentary behaviour: e.g. by providing more precise intervention settings and time windows.

This present study therefore aims to examine tracking of total sedentary time, prolonged sedentary time (defined as time accumulated in sedentary bouts $\geq 10 \mathrm{~min}$ ) and dayto-day variation in total and prolonged sedentary time during childhood, in a large international sample. Previous research indicates that sedentary time and the rate of change in sedentary time may be different for boys and girls and during different phases of childhood and adolescence (e.g. during childhood and the transition from childhood to adolescence) $[4,6]$. Therefore, the moderating effects of gender and age group were examined.

\section{Methods}

\section{Study design and participants}

Data were obtained from the International Children's Accelerometry Database (ICAD, http://www.mrc-epid. cam.ac.uk/research/studies/icad). The ICAD was established to pool data from studies conducted around the world using the Actigraph accelerometer to objectively measure young people's sedentary time and physical activity. A detailed description of the ICAD including aims, design and methods can be found elsewhere [23]. The full database contains data of approximately 37,000 children (aged 3-18 years) from 20 studies in 10 countries. For the purpose of the present study, data were extracted from eight observational studies with longitudinal data available (total $N=14,098$; Table 1 [24-32]). The eight included studies were conducted in five different countries and data were collected between 1997 and 2011. Five studies had two waves of data collection, two studies had three waves and one study had four waves of data available. All included studies obtained relevant ethical approval and appropriate consent.

\section{Measurements}

All studies used waist-worn uniaxial Actigraph accelerometers (models 7164, 71,256 and GT1M; Pensacola, FL, USA), which have acceptable validity for estimating sedentary time in youth $[33,34]$. Raw accelerometer data was re-processed centrally (pampro, Github repository). Higher resolution data was reintegrated to $60 \mathrm{~s}$ epoch 


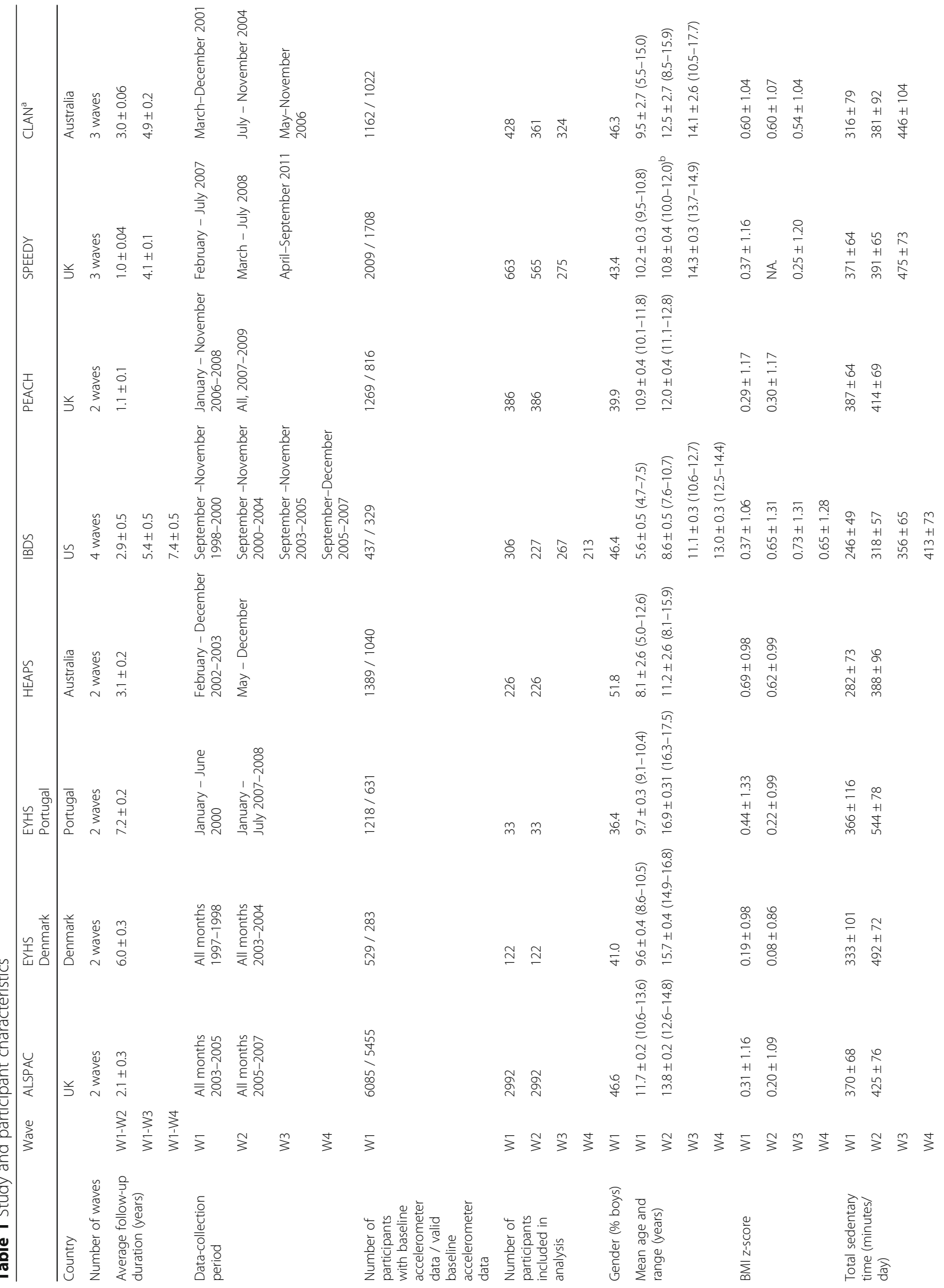




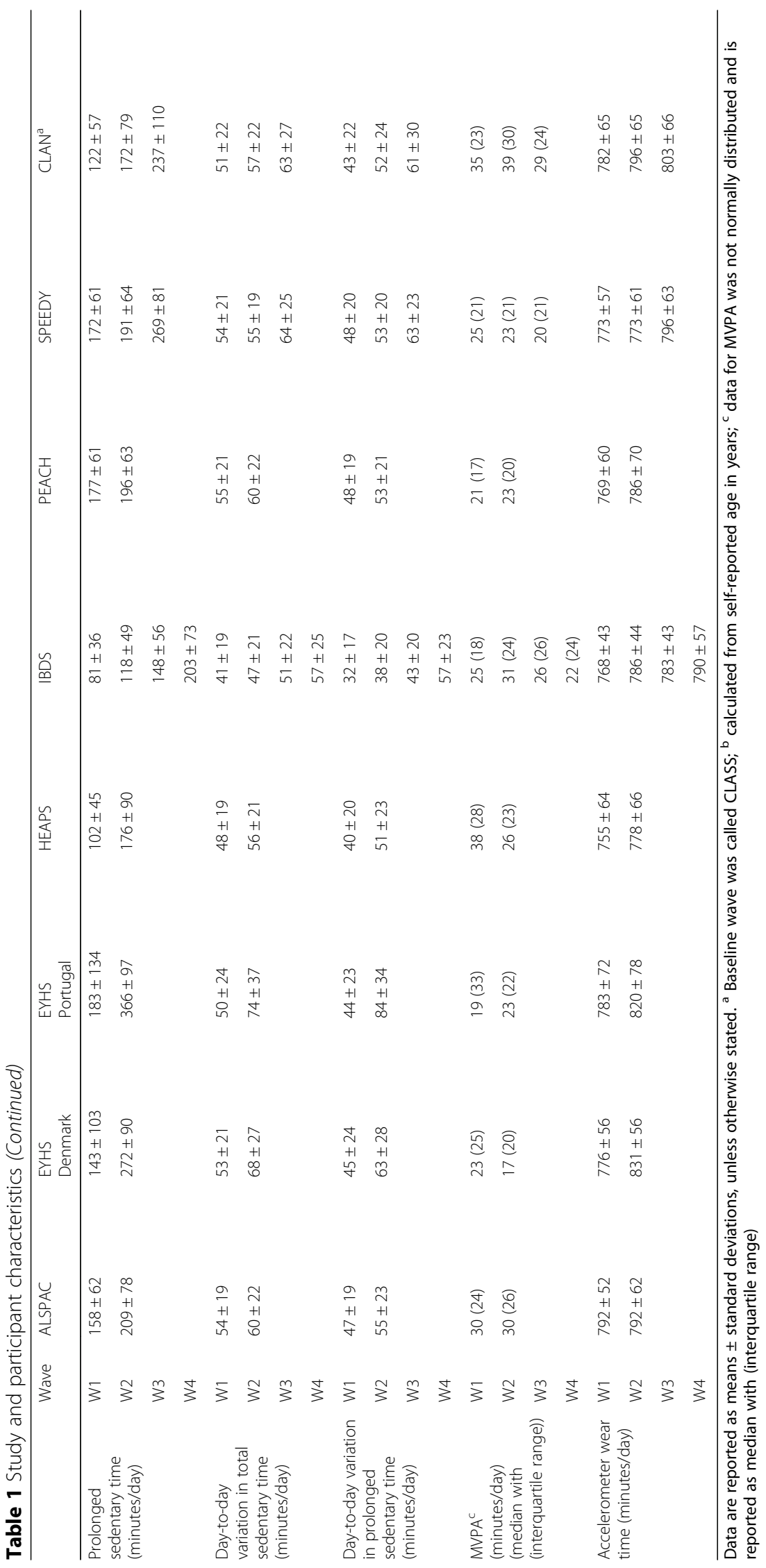


resolution, epochs with an intensity $>30,000 \mathrm{cpm}$ were classified as non-valid and time between midnight and 7 am was discarded. Non-wear time was defined as bouts $\geq 60$ min of consecutive zeros, allowing no tolerance time [35]. A day was defined as valid when the accelerometer was worn for $\geq 480 \mathrm{~min}$ (between $7 \mathrm{am}$ and midnight). Participants were included in the analysis when they provided valid data for at least 4 days, including at least 1 weekend day, both at baseline and at least one follow-up assessment. Total sedentary time was calculated using a cut-point of < 100 counts per minute (CPM) [36, 37]. Prolonged uninterrupted sedentary time was defined as sedentary time accumulated in bouts of at least 10 consecutive minutes at < 100 CPM [35], allowing no tolerance for interruptions [38]. There is currently a lack of consensus on definitions of prolonged sedentary time. We based our decision to use $\geq 10$ min as criteria of prolonged sitting on the paper of Altenburg et al. [35]. This paper pointed out that bouts of $\geq 20$ min are very rare in children. Although bouts of $\geq 5 \mathrm{~min}$ are very common in children, it is unlikely that such short sedentary bouts have health effects. Therefore, we chose $\geq 10$ min to define prolonged sedentary time.

Day-to-day variability in total sedentary time, and in prolonged uninterrupted sedentary time ( $\mathrm{min} /$ day), was calculated as the sum of absolute differences between the values for each measurement day $\left(x_{\mathrm{i}}\right)$ and the mean value $(\bar{x})$, divided by the number of days on which the accelerometer was worn $(N)$ and was calculated for each individual participant.

$$
\frac{\sum\left|x_{i}-\bar{x}\right|}{N}
$$

Moderate-to-vigorous intensity physical activity (MVPA) was calculated for descriptive purposes, using a cut-point of $\geq 3000 \mathrm{CPM}$ [39]. Body mass index (BMI, in $\mathrm{kg} / \mathrm{m}^{2}$ ) was calculated for descriptive reasons as well and expressed as z-scores (BMI z-score) based on gender and age using World Health Organisation reference data [40]. Information on participants' body height and body weight was lacking from SPEEDY wave 2, but was available for all other studies and waves. BMI z-score was therefore not reported for SPEEDY wave 2.

\section{Statistical analyses}

Study and wave specific descriptive characteristics were calculated using SPSS 20.0 (SPSS, Inc., Chicago, IL, USA). For all analyses, Individual patient data (IPD) meta-analyses were performed. Because the ICAD data is hierarchical, multilevel lineair regression modelling with a 4-level structure (country, study, child and repeated observations within the child) was used for all analyses to adjust the regression coefficients for clustering of observations. In order to estimate the annual change (expressed in minutes/day) in total sedentary time, prolonged sedentary time and their day-to-day variation, time was added to the multilevel model. The analyses were adjusted for wear time due to differences across children. For tracking analyses, baseline levels for sedentary time or its day-to-day variation were used as independent variables and the follow-up measurements were used as outcome. If there was more than one follow-up measurement available, data of all follow-up measurements were included in the model. Regression coefficients for baseline levels can be interpreted as longitudinal tracking coefficients. Tracking coefficients were standardized to maximize comparison with other tracking coefficients; standardized coefficients therefore range between 0 (no tracking) and 1 (perfect tracking). Tracking was defined as low when the standardized coefficient was $<0.3$; moderate $0.3-0.6$; and high $>0.6[10,41]$. 'No evidence of tracking' was assigned when the association between baseline and follow-up levels (i.e. the tracking coefficient) had a $p \geq$ 0.05 . Tracking analyses were adjusted for wear time, baseline age, gender and follow-up duration. Moderating effects of gender and age group were examined in separate models by adding interaction terms. For interaction terms at $p<$ 0.05 , tracking analyses were stratified. The variable "age group" consisted of two categories: (1) children (age at baseline and follow-up $\leq 12$ years) and (2) transition from childhood to adolescence (baseline $\leq 12$ years, follow-up > 12 years). Adolescence (age at baseline and follow-up $>12$ years) was not included as a category because only 6 participants belonged to this group. Tracking analyses were conducted using MLwiN version 2.22.

\section{Results}

Data from 14,098 participants was available at baseline, of which 11,284 participants $(80 \%)$ had valid baseline accelerometer data. Five thousand nine hundred ninety-one participants (46\% boys) provided valid accelerometer data at both baseline and at least one follow-up and were included in the analyses. Table 1 presents the participant characteristics per study. Participants were on average 10.3 years old at baseline (range: $4.7-15.0$ years). Participant's follow-up duration ranged between 0.7-8.2 years and was 2.7 years on average. Age of children at follow-up ranged from 7.6 to 17.7 years. At baseline, total sedentary time at study level ranged from 246 to $387 \mathrm{~min} /$ day on average. Prolonged sedentary time at study level ranged from 81 to $183 \mathrm{~min} /$ day on average, representing $33-50 \%$ of total sedentary time. Baseline levels of day-to-day variation in total and prolonged sedentary time at study level ranged from 41 to $55 \mathrm{~min} /$ day and from 32 to $48 \mathrm{~min} /$ day, respectively. For example, a day-to-day variation in total sedentary time of $41 \mathrm{~min}$ can be interpreted as, children's daily time spent sedentary varied by $41 \mathrm{~min}$ from their mean weekly sedentary time. 
Results of the multilevel analyses indicated that total sedentary time increased on average by $21.4 \mathrm{~min} /$ day [95\% confidence interval (95 CI): 19.9-23.0] for each additional year of follow-up and prolonged sedentary time by $20.9 \mathrm{~min} /$ day [95 CI: 19.2-22.7]. Day-to-day variation in total sedentary time increased on average by $2.3 \mathrm{~min} /$ day [95 CI: 1.8-2.9] for each additional year of follow-up and day-to-day variation in prolonged sedentary time increased by $3.4 \mathrm{~min} /$ day [95 CI: 2.8-4.0].

Table 2 shows the results of the tracking analyses. Total $(\mathrm{B}=0.48$ [95 CI: 0,$45 ; 0.50])$ and prolonged $(\mathrm{B}=$ $0.43[0.41 ; 0.45])$ sedentary time tracked moderately in the total sample, while tracking of day-to-day variation in total $(0.04[0.02 ; 0.07])$ and prolonged $(0.07$ [0.04; $0.09])$ sedentary time was low. Regarding differences by gender, interaction terms revealed differences with a $P<$ 0.05 for total and prolonged sedentary time, but these differences were small in size with slightly higher trackingcoefficients for boys (total: 0.51 [0.47; 0.55], prolonged: 0.46 [0.42; 0.49]) than for girls (total: 0.45 [0.42; $0.48]$, prolonged 0.42 [0.39; 0.44$]$. Tracking of day-to-day variation in total and prolonged sedentary time did not differ for boys and girls.

Regarding differences by age group, interaction terms revealed differences with a $\mathrm{P}<0.05$ for total sedentary time and day-to-day variation in prolonged sedentary time. Stratified analyses demonstrated that tracking of total sedentary time was high during childhood $(0.62$ [0.57; 0.67]) and moderate during the transition from childhood to adolescence $(0.44[0.42 ; 0.46])$. We found no evidence for tracking of day-to-day variation in prolonged sedentary time during childhood (0.02 [-0.03; $0.06]$ ), and low tracking in prolonged sedentary time during the transition from childhood to adolescence
(0.09 [0.06; 0.12]). Tracking of prolonged sedentary time and tracking of day-to-day variation in total sedentary time was similar for both age groups ( $p$-values for interaction were 0.22 and 0.14 , respectively).

\section{Discussion}

Total and prolonged sedentary time tracked moderately in young people, while tracking of day-to-day variation in total and prolonged sedentary time was low. Tracking of total sedentary time was higher during childhood than during the transition from childhood to adolescence. Tracking of total and prolonged sedentary time was slightly higher for boys than for girls. Tracking of dayto-day variation was similar for boys and girls.

Our finding that total sedentary time tracked moderately in young people is consistent with previous smaller scale studies that assessed sedentary time objectively $[4,14,15]$. In contrast, Kelly et al. [16] reported low tracking, but this study was conducted in preschool-aged children. Our finding of moderate tracking of total sedentary time is also in line with the conclusions from systematic reviews including mainly studies on TV viewing and screen time $[9,11,12]$. We found that total sedentary time increased on average by $21.4 \mathrm{~min} /$ day for each additional year of follow-up. A novel finding is that this increase was almost entirely due to an increase in prolonged sedentary time (> 10 min bouts; 20.9 $\mathrm{min} /$ day for each additional year). The study of Janssen et al. [4] reported a comparable, although slightly higher, increase in total sedentary time of 24 min per year. Tanaka et al. [5] reported in their review a higher increase of 30 min per year. Factors that may have influenced these differences in annual increase of total sedentary time are differences across studies in age of the included children, follow-

Table 2 Tracking of total and prolonged sedentary time and their day-to-day variation

\begin{tabular}{|c|c|c|c|c|}
\hline & Total sedentary time & $\begin{array}{l}\text { Prolonged } \\
\text { sedentary time }\end{array}$ & $\begin{array}{l}\text { Day-to-day variation in } \\
\text { total sedentary time }\end{array}$ & $\begin{array}{l}\text { Day-to-day variation in } \\
\text { prolonged sedentary time }\end{array}$ \\
\hline Total sample $(n=5991)$ & $\begin{array}{l}0.48[0.45 ; 0.50] \\
p<0.0001\end{array}$ & $\begin{array}{l}0.43[0.41 ; 0.45] \\
p<0.0001\end{array}$ & $\begin{array}{l}0.04[0.02 ; 0.07] \\
p<0.0017\end{array}$ & $\begin{array}{l}0.07[0.04 ; 0.09] \\
p<0.0001\end{array}$ \\
\hline \multicolumn{5}{|l|}{ Moderation by gender ${ }^{b}$} \\
\hline Boys $(n=2757)$ & $\begin{array}{l}0.51[0.47 ; 0.55] \\
p<0.0001\end{array}$ & $\begin{array}{l}0.46[0.42 ; 0.49] \\
p<0.0001\end{array}$ & & \\
\hline Girls $(n=3234)$ & $\begin{array}{l}0.45[0.42 ; 0.48] \\
p<0.0001\end{array}$ & $\begin{array}{l}0.42[0.39 ; 0.44] \\
p<0.0001\end{array}$ & & \\
\hline \multicolumn{5}{|l|}{ Moderation by age group ${ }^{c}$} \\
\hline During childhood $(n=1919)$ & $\begin{array}{l}0.62[0.57 ; 0.67] \\
p<0.0001\end{array}$ & & & $\begin{array}{l}0.02[-0.03 ; 0.06] \\
P=0.21\end{array}$ \\
\hline $\begin{array}{l}\text { During transition from } \\
\text { childhood to adolescence } \\
(n=4050)\end{array}$ & $\begin{array}{l}0.44[0.42 ; 0.46] \\
p<0.0001\end{array}$ & & & $\begin{array}{l}0.09[0.06 ; 0.12] \\
p<0.0001\end{array}$ \\
\hline
\end{tabular}


up duration, included countries as well as accelerometer data reduction criteria.

We observed slightly lower tracking of sedentary time during the transition from childhood to adolescence than during childhood. This may be partly explained by children moving from primary to secondary school during the follow-up period. School transition is accompanied by changes in young people's social and school environment that may explain the larger changes and variability in sedentary time [42, 43], thereby lowering tracking of sedentary time during the transition from childhood to adolescence. In some countries, however, such as the UK, children already attend secondary school at 12 , whereas in other countries, children at this age are still in primary school. Some participants included in the 'child' age group would have therefore moved from primary to secondary school during follow-up, which may have attenuated the tracking estimate for the child age group.

Average total sedentary time at study level ranged from 243 to $375 \mathrm{~min} /$ day at baseline for boys and from 250 to $393 \mathrm{~min} /$ day at baseline for girls. Prolonged sedentary time at baseline ranged between 81 and 171 and 82-206 min/day, repespectively for boys and girls. Although average total and prolonged sedentary time at baseline was slightly higher for girls than for boys, tracking of total and prolonged sedentary time was similar for boys and girls, with slightly higher tracking coefficients for boys. This is in line with the reviews of Biddle et al. [9] and Pearson et al. [12] who concluded little evidence for gender differences in tracking of sedentary behaviour. One previous original study examined gender differences in tracking of accelerometer-assessed sedentary time and found similar tracking coefficients for boys and girls as well [15]. This suggest that tracking of sedentary time is similar for boys and girls.

Tracking of the day-to-day variation in total and prolonged sedentary time was low, with tracking coefficients close to zero. Thus, average values of total and prolonged sedentary time calculated over multiple days track over time, but the day-to-day patterns from which these daily averages are estimated track poorly in young people. This suggests that young people accumulate their sedentary time differently during the week but retain their rank for average total and prolonged sedentary time within the population. The poor tracking of day-to-day patterns in children implicates that sedentary behavior is variable and may therefore be targeted by interventions focusing on various types and settings of sedentary behavior throughout the day and week. Studies on the occurrence and dayto-day variability of specific types of children's sedentary behavior are recommended to provide more insight in their sedentary patterns.

Our finding that total and prolonged sedentary time increase with age and track moderately over time suggests that sedentary behaviour already becomes habitualized during childhood. Studies with a long follow-up period are recommended to examine the degree to which young people's total and prolonged sedentary time track into adulthood.

One key strength of this study is the large harmonised international dataset including accelerometer data. This allowed us to apply consistent data reduction decisions across the different studies included. This study is the first to examine tracking of prolonged sedentary time and the day-to-day variation in total and prolonged sedentary time. However, a limitation may be the limited representativeness of our study population, caused by multiple factors. First, the ICAD-data is not globally representative and data from the UK was relatively overrepresented in this analysis. Moreover, data from individual studies may not be nationally representative due to sampling strategies, non-response, loss to follow-up and baseline samples with valid accelerometer data being different from total study samples. In the present analysis, less than $50 \%$ of the participants with valid accelerometer data at baseline also had valid accelerometer data on at least one follow op measure. Therefore, results should be interpreted and generalised with caution.

\section{Conclusion}

In this international sample of children and adolescents, sedentary time and prolonged sedentary time track moderately in young people while tracking of day-to-day variation in total and prolonged sedentary time was low. This suggests that young people keep their rank within the population moderately stable but the day-to-day pattern in which they accumulate their sedentary time varies over time. Total sedentary time increased on average by 21 $\mathrm{min} /$ day per year and this increase consisted almost completely of an increase in prolonged sedentary time.

\footnotetext{
Abbreviations

$95 \mathrm{Cl}$ : 95\% confidence interval; ALSPAC: Avon Longitudinal Study of Parents And Children; BMI: Body Mass Index; CPM: counts per minute;

CLAN: Children Living in Active Neighbourhoods; EYHS: European Youth Heart Study; HEAPS: Healthy Eating And Play Study; IBDS: lowa Bone Development Study; ICAD: International Children's Accelerometry Database; IPD meta-analyses: Individual patient data meta-analyses; MVPA: Moderateto-vigorous intensity physical activity; PEACH: Personal and Environmental Associations with Children's Health; SD: Standard Deviation; SPEEDY: Sport, Physical activity and Eating behaviour: Environmental Determinants in Young people
}

\footnotetext{
Acknowledgements

We would like to thank all participants and funders of the original studies that contributed data to ICAD. We gratefully acknowledge the past contributions of Prof Chris Riddoch, Prof Ken Judge, Prof Ashley Cooper and Dr. Pippa Griew to the development of ICAD.

The ICAD was made possible thanks to the sharing of data from the following contributors (study name): Prof LB Andersen, Faculty of Education, Arts and Sport, Western Norway University of Applied Sciences, Sogndal, Norway (Copenhagen School Child Intervention Study (CoSCIS)); Prof S Anderssen, Norwegian School for Sport Science, Oslo, Norway (European Youth Heart Study (EYHS), Norway); Prof G Cardon, Department of
} 
Movement and Sports Sciences, Ghent University, Belgium (Belgium PreSchool Study); Centers for Disease Control and Prevention (CDC), National Center for Health Statistics (NCHS), Hyattsville, MD USA (National Health and Nutrition Examination Survey (NHANES)); Dr. R Davey, Centre for Research and Action in Public Health, University of Canberra, Australia (Children's Health and Activity Monitoring for Schools (CHAMPS)); Dr. P Hallal, Postgraduate Program in Epidemiology, Federal University of Pelotas, Brazil (1993 Pelotas Birth Cohort); Prof KF Janz, Department of Health and Human Physiology, Department of Epidemiology, University of lowa, lowa City, US (lowa Bone Development Study); Prof S Kriemler, Epidemiology, Biostatistics and Prevention Institute, University of Zürich, Switzerland (Kinder-Sportstudie (KISS)); Dr. N Møller, University of Southern Denmark, Odense, Denmark (European Youth Heart Study (EYHS), Denmark); Dr. K Northstone, Department of Population Health Sciences, Bristol Medical School, University of Bristol, UK (Avon Longitudinal Study of Parents and Children (ALSPAC)); Dr. A Page, Centre for Exercise, Nutrition and Health Sciences, University of Bristol, UK (Personal and Environmental Associations with Children's Health (PEACH)); Prof R Pate, Department of Exercise Science, University of South Carolina, Columbia, US (Physical Activity in Pre-school Children (CHAMPS-US) and Project Trial of Activity for Adolescent Girls (Project TAAG)); Dr. JJ Puder, Service of Endocrinology, Diabetes and Metabolism, Centre Hospitalier Universitaire Vaudois, University of Lausanne, Switzerland (Ballabeina Study); Prof J Reilly, Physical Activity for Health Group, School of Psychological Sciences and Health, University of Strathclyde, Glasgow, UK (Movement and Activity Glasgow Intervention in Children (MAGIC)); Prof J Salmon, Institute for Physical Activity and Nutrition (IPAN), School of Exercise and Nutrition Sciences, Deakin University, Geelong, Australia (Children Living in Active Neigbourhoods (CLAN) \& Healthy Eating and Play Study (HEAPS)); Prof LB Sardinha, Exercise and Health Laboratory, Faculty of Human Movement, Universidade de Lisboa, Lisbon, Portugal (European Youth Heart Study (EYHS), Portugal); Dr. EMF van Sluijs, MRC Epidemiology Unit \& Centre for Diet and Activity Research, University of Cambridge, UK (Sport, Physical activity and Eating behaviour: Environmental Determinants in Young people (SPEEDY)).

"The ICAD Collaborators include: Prof LB Andersen, Faculty of Teacher Education and Sport, Western Norway University of Applied Sciences, Sogndal, Norway (Copenhagen School Child Intervention Study (CoSCIS)); Prof S Anderssen, Norwegian School for Sport Science, Oslo, Norway (European Youth Heart Study (EYHS), Norway); Dr AJ Atkin, Faculty of Medicine and Heath Sciences, University of East Anglia, UK; Prof G Cardon, Department of Movement and Sports Sciences, Ghent University, Belgium (Belgium Pre-School Study); Centers for Disease Control and Prevention (CDC), National Center for Health Statistics (NCHS), Hyattsville, MD USA (National Health and Nutrition Examination Survey (NHANES)); Dr R Davey, Centre for Research and Action in Public Health, University of Canberra, Australia (Children's Health and Activity Monitoring for Schools (CHAMPS)); Prof U Ekelund, Norwegian School of Sport Sciences, Oslo, Norway \& MRC Epidemiology Unit, University of Cambridge, UK; Dr DW Esliger, School of Sports, Exercise and Health Sciences, Loughborough University, UK; Dr P Hallal, Postgraduate Program in Epidemiology, Federal University of Pelotas, Brazil (1993 Pelotas Birth Cohort); Dr BH Hansen, Norwegian School of Sport Sciences, Oslo, Norway; Prof KF Janz, Department of Health and Human Physiology, Department of Epidemiology, University of lowa, lowa City, US (lowa Bone Development Study); Prof S Kriemler, Epidemiology, Biostatistics and Prevention Institute, University of Zürich, Switzerland (Kinder-Sportstudie (KISS)); Dr N Møller, University of Southern Denmark, Odense, Denmark (European Youth Heart Study (EYHS), Denmark); Dr K Northstone, School of Social and Community Medicine, University of Bristol, UK (Avon Longitudinal Study of Parents and Children (ALSPAC)); Dr A Page, Centre for Exercise, Nutrition and Health Sciences, University of Bristol, UK (Personal and Environmental Associations with Children's Health (PEACH)); Prof R Pate, Department of Exercise Science, University of South Carolina, Columbia, US (Physical Activity in Pre-school Children (CHAMPS-US) and Project Trial of Activity for Adolescent Girls (Project TAAG)); Dr JJ Puder, Service of Endocrinology, Diabetes and Metabolism, Centre Hospitalier Universitaire Vaudois, University of Lausanne, Switzerland (Ballabeina Study); Prof J Reilly, Physical Activity for Health Group, School of Psychological Sciences and Health, University of Strathclyde, Glasgow, UK (Movement and Activity Glasgow Intervention in Children (MAGIC)); Prof J Salmon, Institute for Physical Activity and Nutrition (IPAN), School of Exercise and Nutrition Sciences, Deakin University, Geelong, Australia (Children Living in Active Neigbourhoods (CLAN) \& Healthy Eating and Play Study (HEAPS)); Prof LB Sardinha, Exercise and Health Laboratory, Faculty of Human
Movement, Universidade de Lisboa, Lisbon, Portugal (European Youth Heart Study (EYHS), Portugal); Dr LB Sherar, School of Sports, Exercise and Health Sciences, Loughborough University, UK; Dr EMF van Sluijs, MRC Epidemiology Unit \& Centre for Diet and Activity Research, University of Cambridge, UK (Sport, Physical activity and Eating behaviour: Environmental Determinants in Young people (SPEEDY))."

\section{Authors' contributions}

EvE, KW, TA, AA, JT, EvS, and MC conceived the study. KW managed the analysis of prolonged sedentary time within the ICAD. EVE conducted the statistical analyses with guidance of JT. EvE drafted the manuscript. KW, TA, AA, EvS and MC provided guidance throughout the study. KJ, NM, KN, AP, JS, LS and EvS organized and managed the data collection. All authors contributed to data interpretation and reviewed and revised the manuscript. All authors approved the final manuscript.

\section{Funding}

The pooling of the data was supported by a grant from the National Prevention Research Initiative [Grant Number: G0701877] (http://www.mrc.ac. uk/research/initiatives/national-prevention-research-initiative-npri/). The funding partners relevant to this award are: British Heart Foundation; Cancer Research UK; Department of Health; Diabetes UK; Economic and Social Research Council; Medical Research Council; Research and Development Office for the Northern Ireland Health and Social Services; Chief Scientist Office; Scottish Executive Health Department; The Stroke Association; Welsh Assembly Government and World Cancer Research Fund. This work was additionally supported by the Medical Research Council [MC_UU_12015/3; MC_UU_12015/ 7], Bristol University, Loughborough University and Norwegian School of Sport Sciences. The UK Medical Research Council and the Wellcome Trust (Grant ref.: 102215/2/13/2) and the University of Bristol provide core support for ALSPAC. The European Youth Heart Study (EYHS) Denmark I and II were funded by the Danish Ministry of the Interior and Health, The Danish Ministry of Culture, and The Danish Medical Research Council. Contributions of Evi van Ekris, Teatske ALtenburg and Mai Chinapaw were supported by the Netherlands Organization for Health Research and Development [Grant number 91211057]. The research visit of Evi van Ekris to the University of Cambridge was supported by the EMGO+ Institute for Health and Care Research travel grant. The work was undertaken under the auspices of the Centre for Diet and Activity Research (CEDAR), a UKCRC Public Health Research Centre of Excellence which is funded by the British Heart Foundation, Cancer Research UK, Economic and Social Research Council, Medical Research Council, the National Institute for Health Research, and the Wellcome Trust (MR/K023187/1). Katrien Wijndaele was supported by a British Heart Foundation Intermediate Basic Science Research Fellowship (grant no. FS/12/58/29709) and the Medical Research Council (Unit Programme no. MC_UU_12015/3).

The views and opinions expressed herein are those of the authors and do not necessarily reflect those of any study funders.

\section{Availability of data and materials}

The data that support the findings of this study are available from MRC Epidemiology Unit, Cambridge. But restrictions apply to the availability of these data, which were used under license for the current study, and so are not publicly available. Data are however available from the authors upon reasonable request and with permission of MRC Epidemiology Unit, Cambridge.

\section{Ethics approval and consent to participate}

All individual studies pooled within the International Children's

Accelerometry Database obtained relevant ethical approval.

\section{Consent for publication}

Not applicable.

\section{Competing interests}

The authors declare that they have no competing interests.

\section{Author details}

${ }^{1}$ Department of Public and Occupational Health, Amsterdam Public Health research institute, VU University Medical Center, van der Boechorststraat 7, 1081BT Amsterdam, the Netherlands. ${ }^{2}$ MRC Epidemiology Unit, University of 
Cambridge, Cambridge, UK. ${ }^{3}$ Centre for Diet and Activity Research (CEDAR), MRC Epidemiology Unit, University of Cambridge, Cambridge, UK. ${ }^{4}$ School of Health Sciences, Faculty of Medicine and Health Sciences, University of East Anglia, Norwich, UK. ${ }^{5}$ Department of Epidemiology and Biostatistics, VU University Medical Center, Amsterdam, the Netherlands. ${ }^{6}$ Faculty of Teacher Education and Sport, Western Norway University of Applied Sciences, Sogndal, Norway. ${ }^{7}$ Department of Health and Human Physiology, University of lowa, lowa City, USA. ${ }^{8}$ Research of Childhood Health, University of Southern Denmark, Odense, Denmark. ${ }^{9}$ Department of Population Health Sciences, Bristol Medical School, University of Bristol, Bristol, UK. ${ }^{10} \mathrm{Centre}$ for Exercise, Nutrition and Health Sciences, University of Bristol, Bristol, UK. ${ }^{11} \mathrm{NIHR}$ Bristol Biomedical Research Centre, University Hospitals Bristol NHS FoundationTrust and University of Bristol, Bristol, UK. ${ }^{12}$ Exercise and Health Laboratory, CIPER, Faculdade de Motricidade Humana, Universidade de Lisboa, Lisbon, Portugal.

\section{Received: 18 October 2019 Accepted: 24 April 2020} Published online: 18 May 2020

\section{References}

1. Carson V, Staiano AE, Katzmarzyk P. Physical activity, screen time, and sitting among US adolescents. Pediatr Exerc Sci. 2015;27:151-9.

2. Verloigne M, Loyen A, Van Hecke L, Lakerveld J, Hendriksen I, De Bourdheaudhuij I, et al. Variation in population levels of sedentary time in European children and adolescents according to cross-European studies: a systematic literature review within DEDIPAC. Int J Behav Nutr Phys Act. 2016;13:69.

3. Larouche R, Garriguet D, Gunnell KE, Goldfield GS, Tremblay MS. Outdoor time, physical activity, sedentary time, and health indicators at ages 7 to 14 : 2012/2013 Canadian health measures survey. Health Rep. 2016;27:3.

4. Janssen X, Mann KD, Basterfield L, Parkinson KN, Pearce MS, Reilly JK, et al. Development of sedentary behavior across childhood and adolescence: longitudinal analysis of the Gateshead millennium study. Int J Behav Nutr Phys Act. 2016;13:88

5. Tanaka C, Reilly JJ, Huang WY. Longitudinal changes in objectively measured sedentary behaviour and their relationship with adiposity in children and adolescents: systematic review and evidence appraisal. Obes Rev. 2014;15:791-803.

6. Cooper AR, Goodman A, Page AS, Sherar LB, Esliger DW, van Sluijs EM, et al. Objectively measured physical activity and sedentary time in youth: the International children's accelerometry database (ICAD). Int J Behav Nutr Phys Act. 2015;12:113.

7. Ekris E, Altenburg TM, Singh A, Proper K, Heymans MW, Chinapaw M. An evidence-update on the prospective relationship between childhood sedentary behaviour and biomedical health indicators: a systematic review and meta-analysis. Obes Rev. 2016;17:833-49.

8. de Rezende LFM, Rodriques Lopes M, Rey-López JP, VKR M, do Carmo Luiz O. Sedentary Behavior and Health Outcomes: An Overview of Systematic Reviews. Plos One. 2014;9:e105620.

9. Biddle SJ, Pearson N, Ross GM, Braithwaite R. Tracking of sedentary behaviours of young people: a systematic review. Prev Med. 2010;51:345-51.

10. Twisk JWR, Kemper HCG, Van Mechelen W, Post GB. Tracking of risk factors for coronary heart disease over a 14-year period: a comparison between lifestyle and biologic risk factors with data from the Amsterdam growth and health study. Am J Epidemiol. 1997;145:888-98.

11. Jones RA, Hinkley T, Okely AD, Salmon J. Tracking physical activity and sedentary behavior in childhood: a systematic review. Am J Prev Med. 2013; 44:651-8.

12. Pearson N, Haycraft E, Johnston JP, Atkin AJ. Sedentary behaviour across the primary-secondary school transition: a systematic review. Prev Med. 2017:94:40-7

13. Klitsie T, Corder K, Visscher TL, Atkin AJ, Jones AP, van Sluijs EM. Children's sedentary behaviour: descriptive epidemiology and associations with objectively-measured sedentary time. BMC Public Health. 2013;113:1092.

14. Baggett CD, Stevens J, McMurray RG, Evenson KR, Murray DM, Catellier DJ, et al. Tracking of physical activity and inactivity in middle school girls. Med Sci Sports Exerc. 2008;40:1916.

15. Janz KF, Burns TL, Levy SM. Tracking of activity and sedentary behaviors in childhood: the lowa bone development study. Am J Prev Med. 2005;29:171-8.
16. Kelly LA, Reilly JJ, Jackson DM, Montgomery C, Grant S, Paton JY. Tracking physical activity and sedentary behavior in young children. Pediatr Exerc Sci. 2007;19:51-60.

17. Altenburg TM, Rotteveel J, Dunstan DW, Salmon J, Chinapaw MJ. The effect of interrupting prolonged sitting time with short, hourly, moderate-intensity cycling bouts on cardiometabolic risk factors in healthy, young adults. J Appl Physiol. 2013;115:1751-6.

18. Belcher BR, Berrigan D, Papachristopoulou A, Brady SM, Bernstein SB, Brychta RJ, et al. Effects of interrupting children's sedentary behaviors with activity on metabolic function: a randomized trial. J Clin Endocrinol Metab. 2015;100:3735-43.

19. Carson V, Stone M, Faulkner G. Patterns of sedentary behavior and weight status among children. Pediatr Exerc Sci. 2014;26:95-102.

20. Gabel L, Ridgers ND, Della Gatta PA, Arundell L, Cerin E, Robinson S, et al. Associations of sedentary time patterns and TV viewing time with inflammatory and endothelial function biomarkers in children. Pediatr Obes. 2016;11:194-201.

21. Saunders TJ, Tremblay MS, Mathieu MÉ, Henderson M, O'Loughlin J, Tremblay A, et al. Associations of sedentary behavior, sedentary bouts and breaks in sedentary time with cardiometabolic risk in children with a family history of obesity. PLoS One. 2013;8:e79143.

22. Chastin SF, Egerton T, Leask C, Stamatakis E. Meta-analysis of the relationship between breaks in sedentary behavior and cardiometabolic health. Obesity. 2015;23:1800-10.

23. Sherar LB, Griew P, Esliger DW, Cooper AR, Ekelund U, Judge $K$, et al. International children's accelerometry database (ICAD): design and methods. BMC Public Health. 2011;11:485.

24. Brage S, Wedderkopp N, Ekelund U, Franks PW, Wareham NJ, Andersen LB, et al. Features of the metabolic syndrome are associated with objectively measured physical activity and fitness in Danish children. Diabetes Care. 2004:27:2141-8

25. Golding J, Pembrey M, Jones R. ALSPAC-the Avon longitudinal study of parents and children. Paediatr Perinat Epidemiol. 2001;15:74-87.

26. Janz KF, Burns TL, Torner JC, Levy SM, Paulos R, Willing MC, et al. Physical activity and bone measures in young children: the lowa bone development study. Pediatr. 2001;107:1387-93.

27. Page AS, Cooper AR, Griew P, Davis L, Hillsdon M. Independent mobility in relation to weekday and weekend physical activity in children aged 10-11 years: the PEACH project. Int J Behav Nutr Phys Act. 2009;6:2.

28. Riddoch C, Edwards D, Page A, Froberg K, Anderssen SA, Wedderkopp N, et al. The European youth heart study-cardiovascular disease risk factors in children: rationale, aims, study design, and validation of methods. J physic Act Health. 2005;2:115-29.

29. Salmon J, Campbell KJ, Crawford DA. Television viewing habits associated with obesity risk factors: a survey of Melbourne schoolchildren. Med J Aust. 2006;184:64-7.

30. Sardinha LB, Andersen LB, Anderssen SA, Quitério AL, Ornelas R, Froberg K, et al. Objectively measured time spent sedentary is associated with insulin resistance independent of overall and central body fat in 9-to 10-year-old Portuguese children. Diabetes Care. 2008;31:569-75.

31. Telford A, Salmon J, Timperio A, Crawford D. Quantifying and characterizing physical activity among 5-to 6-and 10-to 12-year-old children: the Children's leisure activities study (CLASS). Pediatr Exerc Sci. 2005;17:266-80.

32. van Sluijs EM, Skidmore PM, Mwanza K, Jones AP, Callaghan AM, Ekelund U, et al. Physical activity and dietary behaviour in a population-based sample of British 10-year old children: the SPEEDY study (sport, physical activity and eating behaviour: environmental determinants in young people). BMC Public Health. 2008;8:388

33. Lubans DR, Hesketh K, Cliff DP, Barnett LM, Salmon J, Dollman J, et al. A systematic review of the validity and reliability of sedentary behaviour measures used with children and adolescents. Obes Rev. 2011:12:781-99.

34. Ridgers ND, Salmon J, Ridley K, O'Connell E, Arundell L, Timperio A. Agreement between activPAL and ActiGraph for assessing children's sedentary time. Int J Behav Nutr Phys Act. 2012;9:15

35. Chinapaw MJM, de Niet M, Verloigne M, De Bourdeaudhuij I, Brug J, Altenburg TM. From sedentary time to sedentary patterns: accelerometer data reduction decisions in youth. PLoS One. 2014;9:e111205.

36. Fischer C, Yildirim M, Salmon J, Chinapaw MJ. Comparing different accelerometer cut-points for sedentary time in children. Pediatr Exerc Sci. 2012;24:220. 
37. Trost SG, Loprinzi PD, Moore R, Pfeiffer KA. Comparison of accelerometer cut points for predicting activity intensity in youth. Med Sci Sports Exerc 2011:43:1360-8.

38. Altenburg TM, Chinapaw MJ. Bouts and breaks in children's sedentary time: currently used operational definitions and recommendations for future research. Prev Med. 2015;77:1-3.

39. Treuth MS, Schmitz K, Catellier DJ, McMurray RG, Murray DM, Almeida MJ, et al. Defining accelerometer thresholds for activity intensities in adolescent girls. Med Sci Sports Exerc. 2004;36:1259.

40. Md O, Onyango AW, Borghi E, Siyam A, Nishida C, Siekmann J. Development of a WHO growth reference for school-aged children and adolescents. Bull World Health Org. 2007;85:660-7.

41. Malina RM. Adherence to physical activity from childhood to adulthood: a perspective from tracking studies. Quest. 2001;53:346-55.

42. Marks J, Barnett LM, Strugnell C, Allender S. Changing from primary to secondary school highlights opportunities for school environment interventions aiming to increase physical activity and reduce sedentary behaviour: a longitudinal cohort study. Int J Behav Nutr Phys Act. 2015;12:59.

43. Morton KL, Corder K, Suhrcke M, Harrison F, Jones AP, van Sluijs EM, et al. School polices, programmes and facilities, and objectively measured sedentary time, LPA and MVPA: associations in secondary school and over the transition from primary to secondary school. Int J Behav Nutr Phys Act. 2016;13:54.

\section{Publisher's Note}

Springer Nature remains neutral with regard to jurisdictional claims in published maps and institutional affiliations.

Ready to submit your research? Choose BMC and benefit from:

- fast, convenient online submission

- thorough peer review by experienced researchers in your field

- rapid publication on acceptance

- support for research data, including large and complex data types

- gold Open Access which fosters wider collaboration and increased citations

- maximum visibility for your research: over $100 \mathrm{M}$ website views per year

At BMC, research is always in progress.

Learn more biomedcentral.com/submissions 